\title{
An Overlooked Term in Assessment of the Potential Sea-Level Rise from a Collapse of the West Antarctic Ice Sheet ${ }^{*}$
}

\author{
Diandong Ren ${ }^{1,2 \#}$, Mervyn Lynch ${ }^{1}$, Lance M. Leslie ${ }^{3}$ \\ ${ }^{1}$ Australian Sustainable Development Institute, Curtin University, Perth, Australia \\ ${ }^{2}$ Department of Imaging and Applied Physics, Curtin University, Perth, Australia \\ ${ }^{3}$ School of Meteorology, The University of Oklahoma, Norman, USA \\ Email: "rendyanyun@gmail.com
}

Received May 9, 2013; revised June 10, 2013; accepted June 20, 2013

Copyright (C) 2013 Diandong Ren et al. This is an open access article distributed under the Creative Commons Attribution License, which permits unrestricted use, distribution, and reproduction in any medium, provided the original work is properly cited.

\begin{abstract}
As to sea level rise (SLR) contribution, melting and setting afloat make no difference for land based ice. Melting of West Antarctic Ice Sheet (WAIS) into water is impossible in the upcoming several centuries, whereas breaking and partially afloat is likely as long as sea waters find a pathway to the bottom of those ice sectors with basal elevation below sea level. In this sense WAIS may be disintegrated in a future warming climate. We reassess the potential contribution to eustatic sea level from a collapse of WAIS and find that previous assessments have overlooked a contributor: slope instability after the cementing ice is removed. Over loading ice has a buttressing effect on slope movements the same way ice shelves hinder the flow of non-floating coastal ice. A sophisticated landslide model estimates a 9-mm eustatic SLR contribution from subsequent landslides.
\end{abstract}

Keywords: Antarctic Ice Sheet; Landslides; Sea Level Rise

\section{Introduction}

At present, the Earth climate is in an interglacial period and the interglacial conditions possibly could continue for another $50 \mathrm{kyr}$ [1]. The relative abundance of glaciers, when compared with two of the last three interglacial periods, suggests that there is still room for sea level rise (SLR) from the current cryosphere.

As the largest potential contributor to SLR, quantifying the Antarctic ice sheet (AIS, Figure 1) total mass balance is important in understanding the global hydrological cycle and its fragile polar ecosystem consequences. The AIS, especially the West Antarctica Ice Sheet (WAIS), has been actively studied [2-8]. Since much of the grounded ice in West Antarctica lies on a bed that inclines inland and extends well below sea level (Figure 2), this bathymetry makes the ice sheet subject to the marine-ice sheet run away instability [8]. Completely melting of WAIS needs $\sim 10^{21} \mathrm{~J}$ of energy, enough for quenching 30 thousands Pinatubo-category Volcanos. This large amount of energy cannot be provided under natural conditions on

\footnotetext{
*This study is supported by Curtin University of Technology.

${ }^{\#}$ Corresponding author.
}

century time frame. However, for marine-based ice sheets to have SLR contribution it is unnecessary for them being completely meltdown. It suffices making them afloat, viable if basal melt water is effectively connected to the oceans.

At present, the primary factor contributing to stability of WAIS is the existence of buttressing ice shelves. Since significant portion of WAIS's inland ice has basal melting, the gravitational driving stress cannot be balanced locally. Ice-shelves have very flat (upper/sub-aerial) surface elevation and do not need too much resistive stress to maintain a balance. The hydrostatic pressure from the submerged portion of ice shelves provide the primary resistive stresses for the neighbouring coastal land ice to balance their gravitational driving stress arising from uneven surface topography. Warming from underneath the marine-based ice sheet, especially that affects ice-shelf viability could unfasten this potentially fragile stability and lead to accelerated creeping of the WAIS. Ice is brittle at higher strain rates, especially under tension, because its melting point diffusivity is around $10^{-15} \mathrm{~m}^{2} / \mathrm{s}$, which is much lower than the $10^{-11} \mathrm{~m}^{2} / \mathrm{s}$ for elemental metals. Accelerated creeping thus implies breaking of 


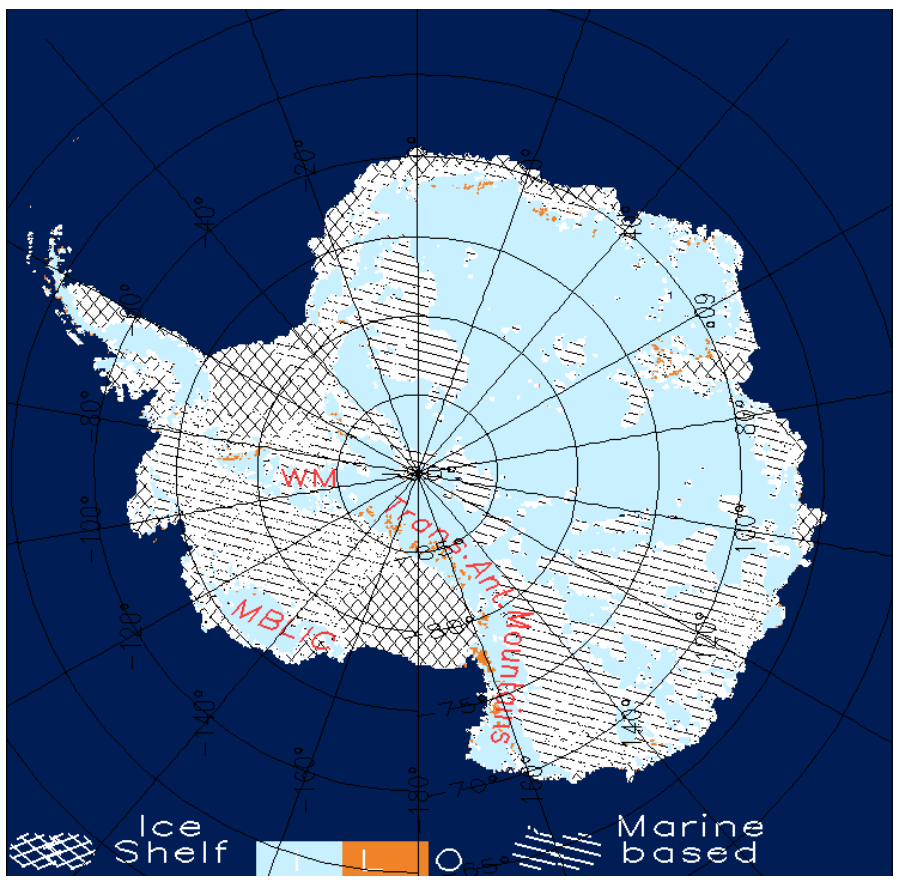

Figure 1. The Antarctica land-ice-ocean mask based on SeaRISE 5-km resolution digital elevation, ice thickness and bedrock elevation data. In the color shading, white is ice, yellow (brown) is bare ground $(\mathrm{L})$ and blue is oceanic grids. The ice shelves are cross-hatched areas; land ice with base under sea level (marine based) also is hatched. West Antarctica has far more complicated ice-water-bedrock configurations than the rest Antarctica. WAIS is defined as the ice sector confined by the Transantarctica mountains and the $40^{\circ} \mathrm{W}$. Ice shelves are essentially floating and have no extra sea level rise contribution when melt. The Peninsula has very limited ice volume $\left(<3.3 \times 10^{4} \mathrm{Gt}\right)$ compared with the $2.8 \times 10^{6} \mathrm{Gt}$ land-based ice of WAIS. This study thus focuses on the landslides after de-glaciation of marine based ice sheet confined by Marie Byrd Land Ice Cap (MBLIC) and Whitmoor Mountains ("WM").

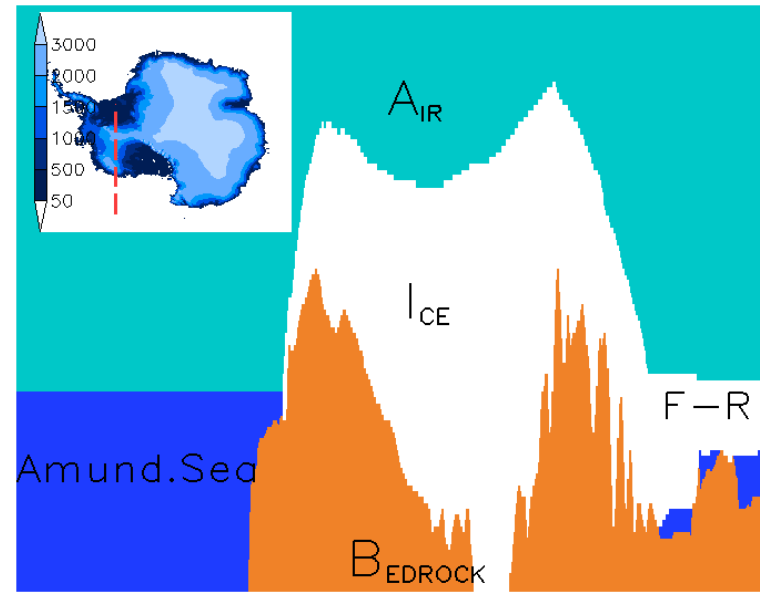

(a)

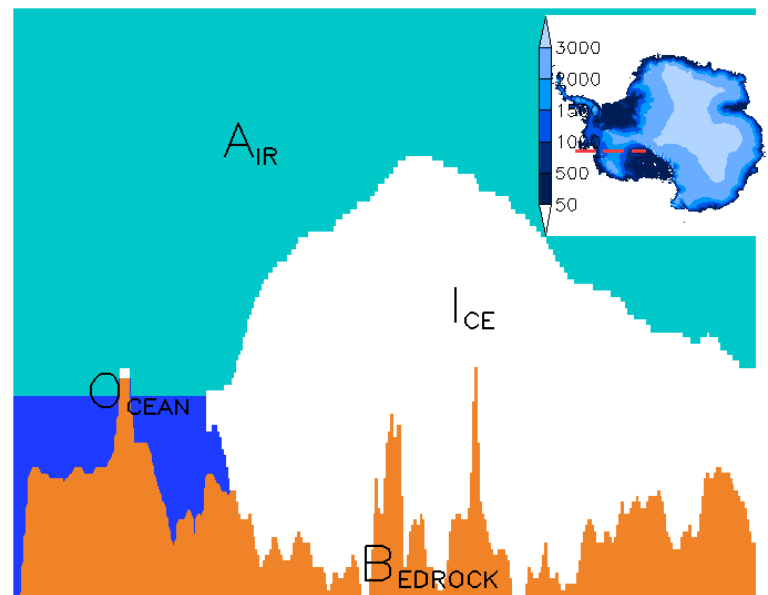

(b)

Figure 2. The West Antarctica land-ice-ocean mask based on SeaRISE 5-km resolution digital elevation, ice thickness and bedrock elevation data. In the color shading, white is ice, yellow (brown) is bedrock and blue is ocean. Left panel is a cross-section along the F-R shelf/Amundsen direction, as indicated in the inset (red dashed line). Right panel is along the Siple coast direction, as the red line in the inset. In a future warming climate, ocean waters are likely rushing to the "soft belly" of WAIS through Siple coast pathway. The extensive troughs (if ice is removed) extend to depth of more than $2 \mathrm{~km}$ at places (a). Color-shading in the insets is surface elevation over Antarctica ice sheet.

WAIS. At the same time, once ice shelves are removed, the pathway for seawater to erode marine based ice sheet is open. With the breaking of ice, those sectors with thickness less than $h_{b} \rho_{w} / \rho_{i}$, with $h_{b}$ the bedrock elevation, $\rho_{w}=1028 \mathrm{~kg} \cdot \mathrm{m}^{-3}$ the density of sea water and $\rho_{i}=918 \mathrm{~kg} \cdot \mathrm{m}^{-3}$ the density of ice, can actually be set 
afloat and have SLR consequences.

Warming factors can in the form of drastic increase of geothermal as a consequence of large, sustained volcano eruptions, which is of very low probability but cannot be discarded outright because of the likely high impact, or in the form of more gradual but widespread oceanic and atmospheric warming driven by anthropogenic greenhouse effects, which is assumed to be salient in the upcoming century [9]. We still do not know the exact timing of the WAIS collapse and this study re-examine the seal level contribution from collapse of the WAIS, a possibility initially proposed by Mercer [2].

Mercer's estimate is based on reasoning as elucidated by Oppenheimer [3]. As WAIS is disintegrated, the vacant below present sea level will be occupied by seawater. The net amount of contribution would be the water equivalent of the disintegrated ice adjusted to account for the volume below sea level $\left(V_{b}\right)$ and also for the postglacial rebound of the bedrock $\left(V_{r}\right)$. Figure 3(b) illustrates the sea level rise under this theory. The sea level rise can be expressed as $V_{a} \frac{\rho_{i}}{\rho_{w}}+V_{b} \frac{\rho_{i}-\rho_{w}}{\rho_{w}}+V_{r}$, where $V_{a}$ is ice volume above sea level. Recently, Bamber et al. [7] made a major stride over the original estimate of Mercer [2] by using non-static bathymetry from a sophisticated Earth model, and considered that only a portion of WAIS satisfy the marine ice sheet instability hypothesis and can actually be floated.

However, this still overlooks a fact that ice overlain bedrock is an ideal configuration for rock erosions and producing large amount of granular material, especially beneath the Marie Byrd Land and the Siple coast [10]. Loading of thick ice above slopes reduces landslide occurrence because of the large confining pressure and also because granular debris are effectively cemented by ice crystals. Inevitably after the removal of the WAIS, landslides will further change the basin shape (Figure 3(c)), on time scales much faster than the basin rebound. In principle, only the debris that is originally above sea level has SLR contribution when sliding to places below sea level $\left(V_{g}\right)$. Sea level rise can be expressed as $\left(V_{a}+V_{b}\right) \rho_{i} / \rho_{w}-V_{b}+V_{r}+V_{g}$. We estimate $V_{g}$ using SEGMENT-landslide [11-13] model driven by meteorological parameters provided by coupled climate models.

\section{Data and Methods}

SEGMEN-landslide explicitly accounts for soil mechanics, vegetation transpiration and root mechanical reinforcement, and relevant hydrological processes. It considers non-local dynamic balance of the three-dimensional topography, soil thickness profile, basal conditions, and vegetation coverage [11] in determining the prognostic fields of the driving and resistive forces, and de- scribes the flow fields and the dynamic evolution of thickness profiles of the medium considered. SEGMENT is a thoroughly tested process-based modeling system for monitoring and predicting landslides and their ecosystem implications (e.g. Ref. 12). Application to polar environment of WAIS poses less challenge for SEGMENTlandslide because the vegetation processes are not an issue. In addition, rainfall morphology, which is critical for storm-triggered landslides, is not a concern because solid precipitation dominates over WAIS. Monthly mean atmospheric forcing parameters suffice for driving the temperature solver to estimate frozen soil mechanical properties. Three independent CGCMs (MPI-ECHAM, NCAR CCSM3 and MIROC3.2-hires, see http://www-pcmdi.llnl.gov/ipcc/about_ipcc.php) are chosen for their relatively fine resolution and for providing all atmospheric parameters required by SEGMENTlandslide.

The subglacial particle properties of WAIS are specified according to studies using boreholes and seismic methods $[14,15]$. The rocks are mostly volcanic and the basalt clasts are of sizes of $\sim 10 \mathrm{~cm}$. Loose, ice-cemented volcanic debris also are wide spread around Mt Waesche $\left(77^{\circ} \mathrm{S}\right.$ and $\left.130^{\circ} \mathrm{W}\right)$ and northern Antarctica Peninsula and its constituent blocks. In assigning granular particle sizes, geothermal pattern also are referenced because repeated phase changes at the interface of ice/rock arguably are the most efficient means of erosion and reducing the granular particle sizes. A high-resolution digital elevation map (DEM) is a key input for slope stability analyses. SeaRISE project (http://websrv.cs.umt.edu/isis/index.php) provides surface DEM at $5 \mathrm{~km}$ horizontal resolution in a South Polar Stereographic projection. The actual sphere resolution is higher at WAIS, but still coarser than 1000 m. Radarsat-1 SAR sensor via Modified Antarctic Mapping Mission (MAMM [16]), as by-product, provides slope information at $200 \mathrm{~m}$ resolution. A $200 \mathrm{~m}$ resolution surface DEM is obtained by combining the SeaRISE and MAMM data. With these data and assuming no major geothermal disturbance from volcano eruptions, SEGMENT-landslide simulation indicates that, except very limited northern areas such as the Deception island, where avalanches seem likely and involved very limited mass redistribution $\left(<10^{5} \mathrm{~m}^{3}\right)$, elsewhere on the present WAIS is stable.

In addition to mechanical properties such as particle size, porosity, bulk density, cohesion and repose angle, the thickness of the granular material is critical in determining the magnitude of the landslides. The granular thickness on slopes underneath the present WAIS is inversely retrieved using SEGMENT-ice, constrained by the goodness of fit between model simulated and observed [16] surface ice velocity, over entire AIS. Figure 4 is the distribution of the estimated granular material 

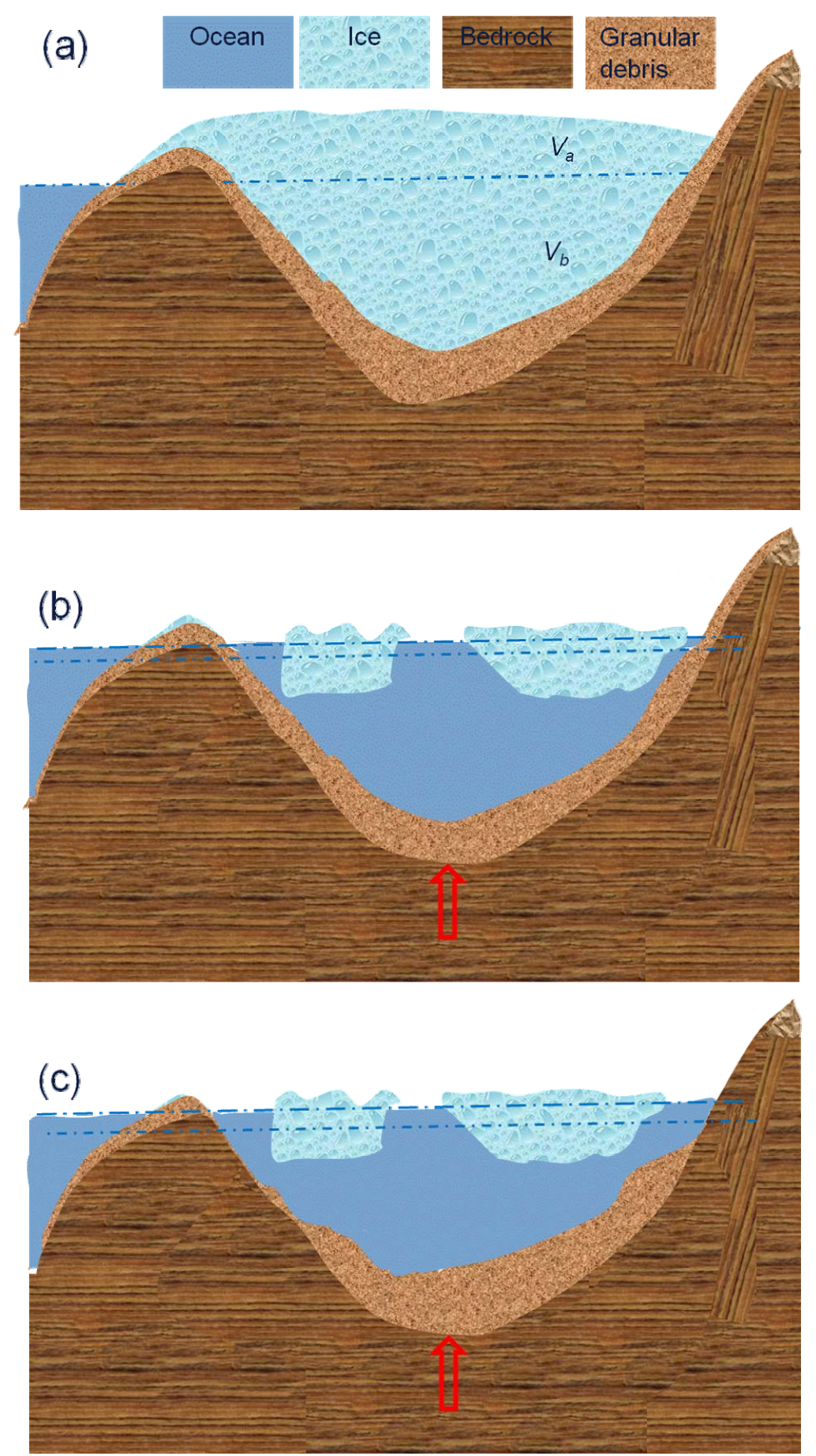

Figure 3. Sketch illustrating eustatic sea level rise after disintegration of WAIS. Panel (a) is the ice-bedrock configuration before WAIS disintegration. As WAIS is disintegrated, the vacant below future sea level will be occupied by seawater. The net contribution would be the water equivalent of the integrated ice adjusted to account for the volume below sea level $\left(V_{b}\right)$ and also for the postglacial rebound of the bedrock (red arrow, $V_{r}$ ). Panel (b) illustrates the sea level rise under this hypothesis. Sea level rise can be expressed as $V_{a} \frac{\rho_{i}}{\rho_{w}}+V_{b} \frac{\rho_{i}-\rho_{w}}{\rho_{w}}+V_{r}$. Inevitably after the removal of the WAIS, landslides (primarily from Marie Byrd Land) will further change the basin shape (c). In principle, only the debris sit originally above sea level has sea level rise contribution after sliding down-slope to places below sea level $\left(V_{g}\right)$. Sea level rise can be expressed as $\left(V_{a}+V_{b}\right) \frac{\rho_{i}}{\rho_{w}}-V_{b}+V_{r}+V_{g}$. What the ice shelf is to the inland coastal land ice is exactly what the land ice to slope stability. 


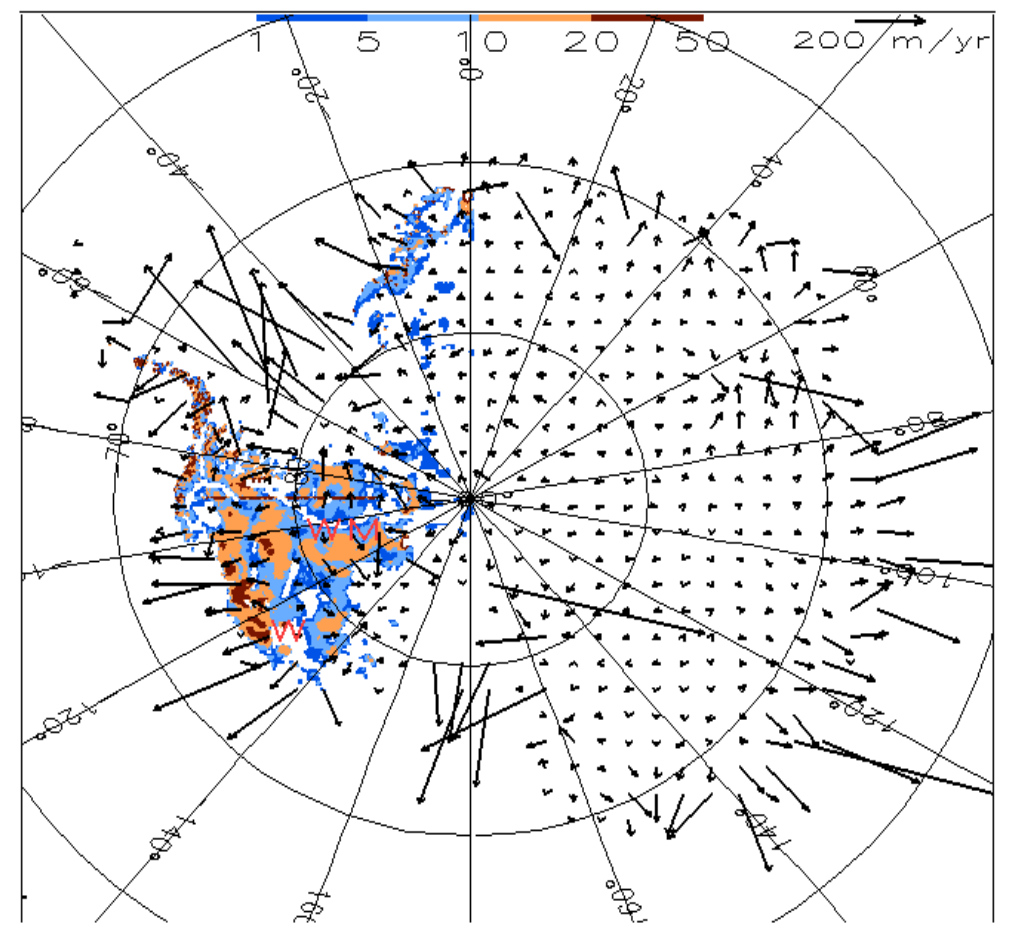

Figure 4. Upon convergence of the optimization procedure, SEGMENT-ice simulated surface velocities over Antarctica ice sheet (vector arrows) and the retrieved granular material depth under the overlain ice (color shading, in meters) over WAIS. The top portion of Mountain Waesche ("W") and the ridge of Whitmoor Mountains ("WM") has shallow debris accumulation $(<1 \mathrm{~m})$. The retrieval is an optimization process. Magnitudes of surface ice velocity are sensitive to the thickness of basal granular material. Based on this sensitivity relationship, repeated runs of the ice model are performed with present ice geometry and ice temperature profiles, but (automatically) varying granular layer thickness, to best fit the observed surface ice velocities. The metric for goodness of fit of the modelled and observed velocity fields is defined as:

$\sum\left\|\overrightarrow{V_{\text {obs }}}-\overrightarrow{V_{\text {model }}}\right\|=\sum \sqrt{\left(u_{\text {obs }}-u_{\text {model }}\right)^{2}+\left(v_{\text {obs }}-v_{\text {model }}\right)^{2}+\left(w_{\text {obs }}-w_{\text {model }}\right)^{2}}$, where $u, v$ and $w$ are components of the full vector velocity. Subscriptions "obs" and "model” mean respectively observed and modeled velocities. The observed ice velocities are obtained from Radarsat-1 SAR sensor via Modified Antarctic Mapping Mission (MAMM, Jezek 2008). Because the seven regional composite of MAMM do not cover the entire Antarctica Ice Sheet (with a "polar hole"), the summation in the metric is only over regions with MAMM observations. Upon convergence, the overall agreement between modelled and observed velocities is very satisfactorily with correlation coefficients 0.92 for direction and 0.90 for magnitude, respectively.

thickness over West Antarctica. This is the initial sliding material thickness.

We then performed the experiments to estimate possible landslides contribution to sea level rise as WAIS disintegrates. Starting from a configuration as in Figure 3(b), or Bamber et al. [7] anticipated results of SLR. The SLR contribution is estimated with the following method. In SEGMENT-landslide, a vertical integration of the incompressible continuity equation, with bedrock rebound rate as lower boundary condition, gives:

$$
\frac{\partial h}{\partial t}=w_{b}-\frac{1}{R \cos \phi} \int_{0}^{1}\left(\frac{\partial U}{\partial \theta}+\frac{\partial V \cos \phi}{\partial \phi}\right) H d s
$$

where $t$ is time, $\theta$ is longitude, $\phi$ is latitude, $U$ and $V$ are horizontal velocity components, and $H$ is the local thickness of the sliding material. Equation (1) is the temporal evolution of the surface elevation $(h)$. It varies with velocity fields and boundary sources $\left(w_{b}\right)$. In Equation (1), it is assumed that the Earth's radius $(R)$ is much larger than the alluvial thickness. Changes in surface elevation multiplied by grid area gives the volume ice loss for that grid. The total sea level rise contribution is the summation over the grids with basal elevation above sea level.

\section{Results and Discussion}

Figure 5 is the surface elevation changes of the bare slopes, and for areas under seawater, the bedrock elevation changes. Landslides can cause certain areas accumulate more than $200 \mathrm{~m}$ of sliding material. The most significant places of volcanic rock and silt debris accumulation are close to Siple coast. However, the source region of the sliding material is primarily the Marie Byrd Land's southeast facing slopes ( $86 \%$ of the accumulated sliding material). Contribution from Whitmoor Mountains are relatively small $(<10 \%)$. This fact is primarily from the existing granular material depths on the slopes 


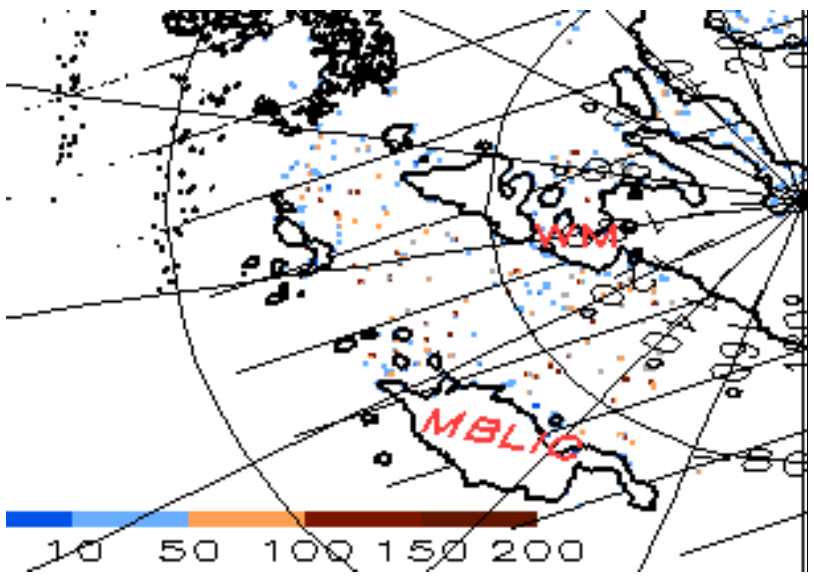

Figure 5. Areas with bedrock elevation increase over 5 meters, as a result of landslides accompanying the deglaciation of WAIS, are color shaded (m). The bedrock zero elevation contour lines are shown, and areas with bedrock elevation below sea level are hatched. Landslide scares are everywhere on the slopes, with localized pairs of elevation increase and decrease. However, regions accumulated most of the sliding material ( $>5 \mathrm{~m}$ depth) are almost all lying below sea level. Marie Byrd Land Ice Cap (MBLIC) and Whitmoor Mountains (WM) are labelled for references. The south east facing slopes of MBLIC contribute most of the sliding material.

(Figure 4). The total volume of the scars on the slopes at elevation above sea level, or equivalently the reduction of the basin volume (under sea level part), is $3220 \mathrm{~km}^{3}$, approximately $0.902 \mathrm{~cm}$ eustatic sea level rise. This amount, although small compared to the $\sim 3.3 \mathrm{~m}$ eustatic sea level rise from the collapsed WAIS [7], is added to the eustatic sea level with very short time delay, essentially closely following the steps of ice disintegration. If the fast scenario [7] realises, the economic cost to world cities from the additional $0.902 \mathrm{~cm}$ is not a simple linear addition to the $3.3 \mathrm{~m}$ sea level rise. In contrast, the contribution from rebound of the basin bottom takes over 10,000 years to finish, provide enough time for human adaptation and mitigation measures to be tested.

The landslides we considered are primarily associated with the granular material as the ice bonds melt and when the solid ice loading are removed. Two most frequent trigger mechanisms for large-scale landslides, rainstorms and earthquakes both are negligible. The former is apparent from year round low air temperature over WAIS. Earthquakes also are rare at Antarctica in general and WAIS in specific, as the Antarctica plate now has only a very small proportion associated with subduction [17] and is bounded by constructive and conservative margins. Thus, our estimates are likely fully representative of the landslides caused extra sea level rise as WAIS disintegrates. The scarp sizes and the maximum attainable sliding speed are both sensitive to the WAIS disintegration scenarios but the total volume of the sliding material in- volved are amazingly a conservative property insensitive to fast/slow scenarios as defined in Ref. [7].

\section{REFERENCES}

[1] A. Berger and M. Loutre, "An Exceptionally Long Interglacial Ahead?” Science, Vol. 297, No. 5585, 2002, pp. 1287-1288. doi:10.1126/science. 1076120

[2] J. H. Mercer, "Antarctic Ice Sheet and $\mathrm{CO}_{2}$ Greenhouse Effect: A Threat of Disaster," Nature, Vol. 271, 1978, pp. 321-325. doi:10.1038/271321a0

[3] M. Oppenheimer, "Global Warming and the Stability of the West Antarctica Ice Sheet," Nature, Vol. 393, 1998, pp. 325-332. doi:10.1038/30661

[4] D. Vaughan, "Recent Trends in Melting Conditions on the Antarctic Peninsula and Their Implications for IceSheet Mass Balance and Sea Level," Arctic Antarctic and Alpine Research, Vol. 38, No. 1, 2006, pp. 147-152. doi:10.1657/1523-0430(2006)038[0147:RTIMCO]2.0.CO :2

[5] M. R. Van den Broeke, W. J. van de Berg and E. van Meijgaard, "Snowfall in Coastal West Antarctica Much Greater than Previously Assumed," Geophysical Research Letters, Vol. 33, No. 2, 2006, Article ID: L02505. doi:10.1029/2005GL025239

[6] E. Rignot, J. Bamber, M. van den Broeke, C. Davis, Y. Li, W. van de Berg and E. van Meijgaard, "Loss of the Antarctic Ice Sheet from Dynamic Thinning," Nature Geoscience, Vol. 1, 2008, pp. 106-110. doi:10.1038/ngeo102

[7] J. L. Bamber, R. Riva, B. Vermeersen and A. LeBrocq, "Reassessment of the Potential Sea-Level Rise from a Collapse of the West Antarctic Ice Sheet," Science, Vol. 324, No. 5929, 2009, pp. 901-903. doi:10.1126/science.1169335

[8] I. Joughin and R. Alley, "Stability of the West Antarctic Ice Sheet in a Warming World," Nature Geosciences, Vol. 4, No. 8, 2011, pp. 493-571. doi:10.1038/ngeo1194

[9] Intergovernmental Panel on Climate Change (IPCC), "Climate Change 2007: The Physical Science Basis," Cambridge University Press, Cambridge, 2007.

[10] D. MacAyeal, "Large-Scale Ice Flow over a Viscous Basal Sediment: Theory and Application to Ice Stream B, Antarctica," Journal of Geophysical Research, Vol. 94, No. B4, 1989, pp. 4071-4087. doi:10.1029/JB094iB04p04071

[11] D. Ren, L. M. Leslie and D. J. Karoly, "Landslide Risk Analysis Using a New Constitutive Relationship for Granular Flow," Earth Interactions, Vol. 12, 2008, pp. 116. doi:10.1175/2007EI237.1

[12] D. Ren, J. Wang, R. Fu, D. Karoly, Y. Hong, L. M. Leslie, C. Fu and G. Huang, "Mudslide Caused Ecosystem Degradation Following Wenchuan Earthquake 2008," Geophysical Research Letters, Vol. 36, No. 5, 2009. doi:10.1029/2008GL036702

[13] D. Ren, R. Fu, L. M. Leslie, D. J. Karoly, J. Chen and C. Wilson, "A Multirheology Ice Model: Formulation and Application to the Greenland Ice Sheet," Journal of Geophysical Research: Atmospheres, Vol. 116, No. D5, 2011, Article ID: D05112, doi:10.1029/2010JD014855 
[14] C. Bentley, In: R. J. Tinguey, Ed., Geography of Antarctica, Oxford University Press, Oxford, 1991, pp. 335-364.

[15] H. Englehardt, et al., "Physical Conditions at the Base of a Fast Moving Antarctica Ice Stream," Science, Vol. 248, No. 4951, 1990, pp. 57-59. doi:10.1126/science.248.4951.57

[16] K. Jezek, "Observing the Antarctic Ice Sheet Using the
RADARSAT-1 Synthetic Aperture Radar," Polar Geography, Vol. 27, No. 3, 2003, pp. 197-209. doi:10.1080/789610167

[17] I. Norton, "Paleomotion between Africa, South America, and Antarctica, and Implications for the Antarctic Peninsula," In: C. Craddock, Ed., Antarctic Geoscience, University of Wisconsin Press, Madison, 1982, pp. 99-106. 